\title{
Decoronation as an option for ridge preservation prior to implant placement
}

\author{
Miroslav Dragović ${ }^{1}$, Marko Pejović1, Jelena Stepić1, Svetlana Dragović2 ${ }^{2}$ Snježana Čolić \\ 'University of Belgrade, School of Dental Medicine, Department of Oral Surgery, Belgrade, Serbia; \\ 2University of Belgrade, School of Dental Medicine, Department of Prosthodontics, Belgrade, Serbia
}

\begin{abstract}
SUMMARY
Decoronation is a surgical procedure based on idea of sectioning tooth crown and maintaining the root in situ with intention to preclude occurrence of severe deformities of bone and soft tissue which may aggravate later rehabilitation of patient.

The aim of this report is to present the use of decoronation in a young adult patient as a solution in order to preserve sufficient amount of bone for delayed implant placement and decrease volume of grafting material to a minimum. Obtained results showed this procedure may greatly improve anatomical conditions for implant placement while reducing invasiveness and required financial means.
\end{abstract}

Keywords: decoronation; implant placement; ridge preservation

\section{INTRODUCTION}

Decoronation was firstly introduced by Malmgren et al. more than 30 years ago [1]. However, up to date there is scarce literature data concerning this concept. Basic idea of this method is removing the crown and maintaining the root of a tooth [2]. Originally proposed as a treatment protocol for ankylosed incisors in children after traumatic avulsion, this method revolutionized therapeutic approach to ankylosed teeth and improved conditions for an implant therapy after skeletal growth is finished.

Although this method often leads to root resorption and its replacement with bone, the width of alveolar ridge maintains unaffected [3,4]. Further, due to alveolar ridge preservation implant surgery may be minimized to a great extent [5]. This impact is explained by the following two mechanisms. Initially, after removing crown $1-2 \mathrm{~mm}$ below cervical bone clot organization is inevitable and consequently bone forming cells and growth factors lead to biologic bone development. Secondly, by sectioning tooth below the level of the osseous crest interdental and circumferential periodontal fibers are detached allowing for adjacent teeth to erupt. As this eruption of the adjacent teeth progresses bone apposition on the top of interdental septum occurs [2].

On the other hand, alveolar socket and ridge preservation using various grafting materials is well known method used to compensate for bone resorption and provide adequate bone volume for an implant placement [6]. Nevertheless, economic aspects or willingness to avoid additional surgical trauma required for earning autologous bone are sometimes the main reasons that motivate patient to opt for a low - budget prosthodontic solution after tooth failure.

The aim of this report was to present tooth decoronation in a young adult patient as a solution for preserving sufficient amount of bone for delayed implant placement and decrease volume of grafting material to a minimum. The second objective was to increase the volume of (keratinized) soft tissue thus minimizing surgical trauma.

\section{CASE REPORT}

A 20 years old female patient was clinically and radiologically examined at the Department of Oral Surgery, School of Dental Medicine University of Belgrade. Having found non-salvageable maxillary left first premolar indicated for extraction patient was advised to undergo implant therapy due to intact canine and good condition of the second premolar (Figure 1). However, due to financial reasons, patient was not able to do either immediate extraction and implant placement or alveolar socket preservation. Besides, patient was not psychologically prepared for surgical procedure. Therefore, decoronation was proposed as a temporary socket preservation method in order to help patient by avoiding usage of bone substitute and collagen membrane during this phase and lowering the costs. Decoronation was done using diamond bur under copious saline irrigation in accordance with recommendation from the literature [1]. Technique was modified by omitting horizontal incision and flap rising (Figure 2).

After a period of five months patient decided to proceed with implant therapy. Owing to excellent healing of soft tissue (Figure 3A) crestal incision was made including mesial and distal papilla and flap was raised without releasing incisions. What was surprising is an outstanding amount of bone that had to be removed to access submerged roots (Figure 3B). Minimally traumatic extraction of roots was done using periotomes (Figure 4A-C). In line with standard drilling protocol standard diameter bone 


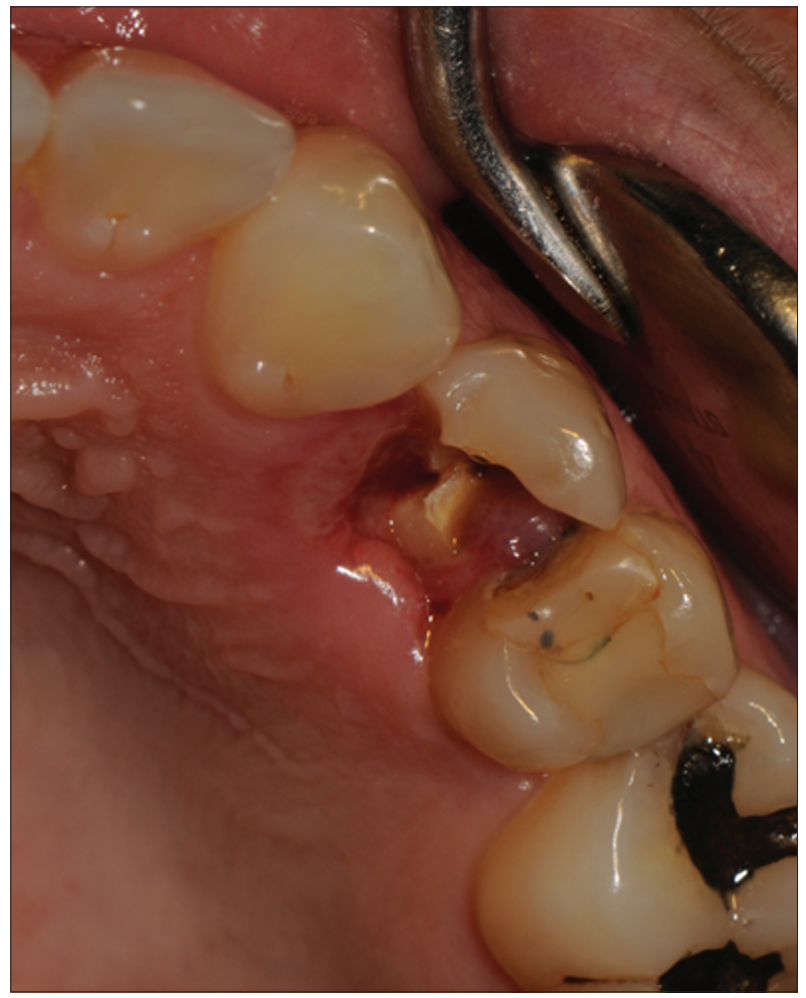

Figure 1. Clinical finding of tooth indicated for extraction Slika 1. Klinički prikaz zuba indikovanog za ekstrakciju
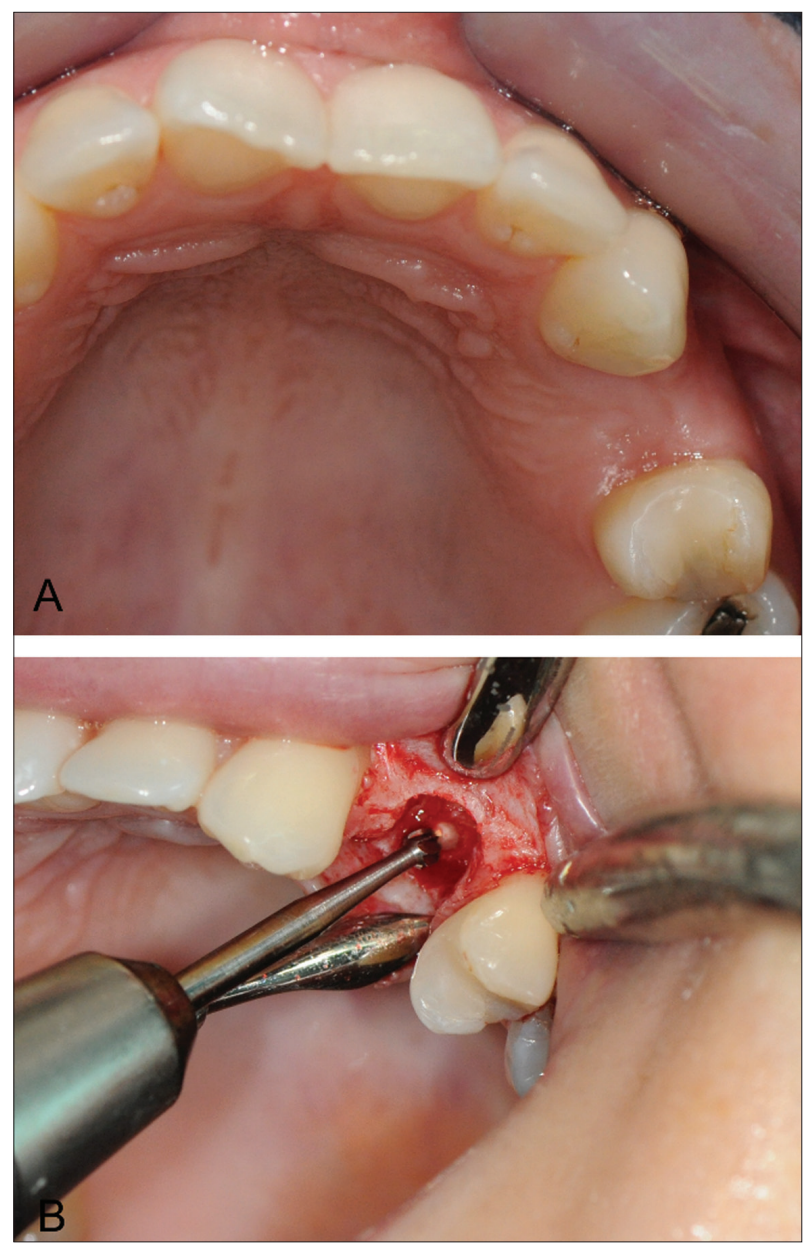

Figure 3. Healing after 5 months $(A)$; bone removal in order to extract roots (B)

Slika 3. Zarastanje posle pet meseci (A); uklanjanje kosti radi vađenja korenova (B)

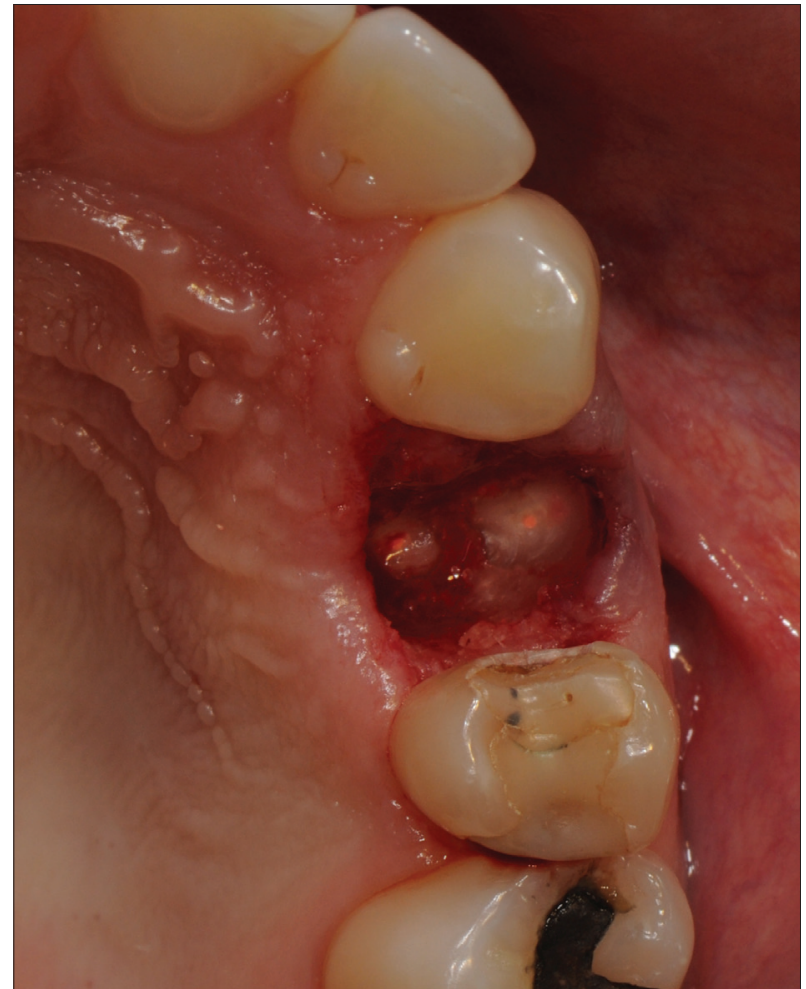

Figure 2. Decoronation without flap elevation

Slika 2. Dekoronizacija (uklanjanje krunice zuba) bez podizanja flapa
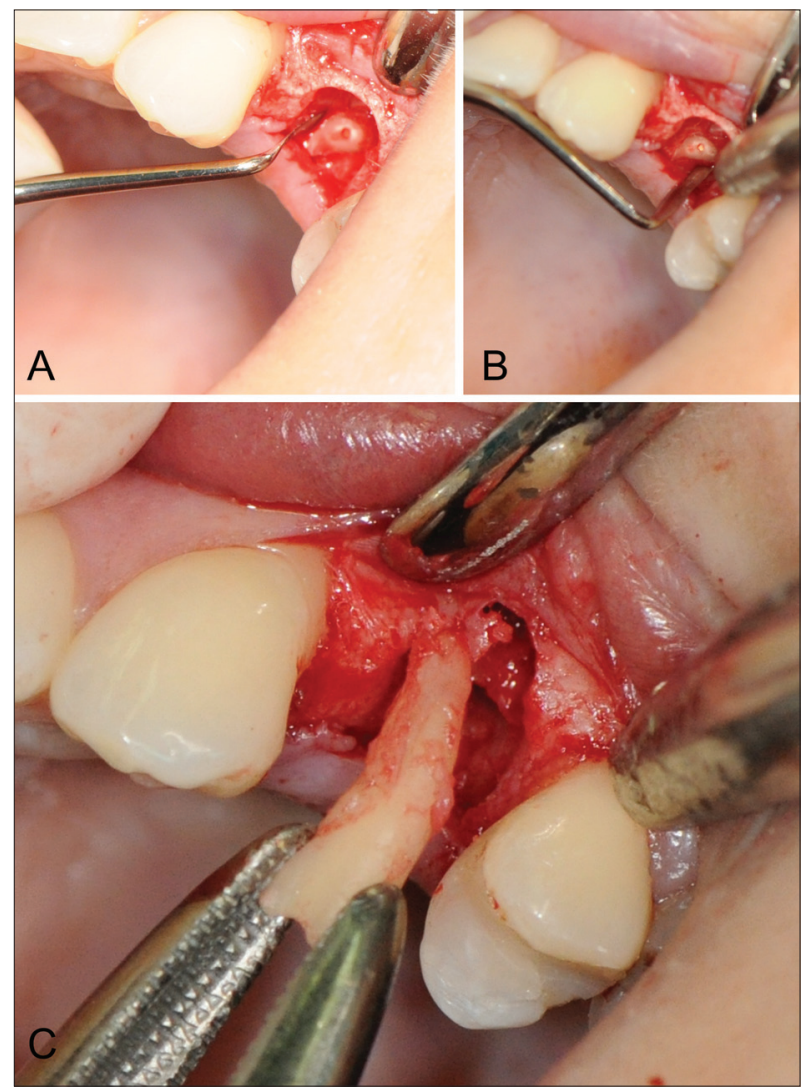

Figure 4. Minimally traumatic extraction of roots using periotomes (A, B); buccal root extracted (C)

Slika 4. Minimalno invazivno vađenje korenova upotrebom periotoma (A, B); bukalni koren izvađen (C) 

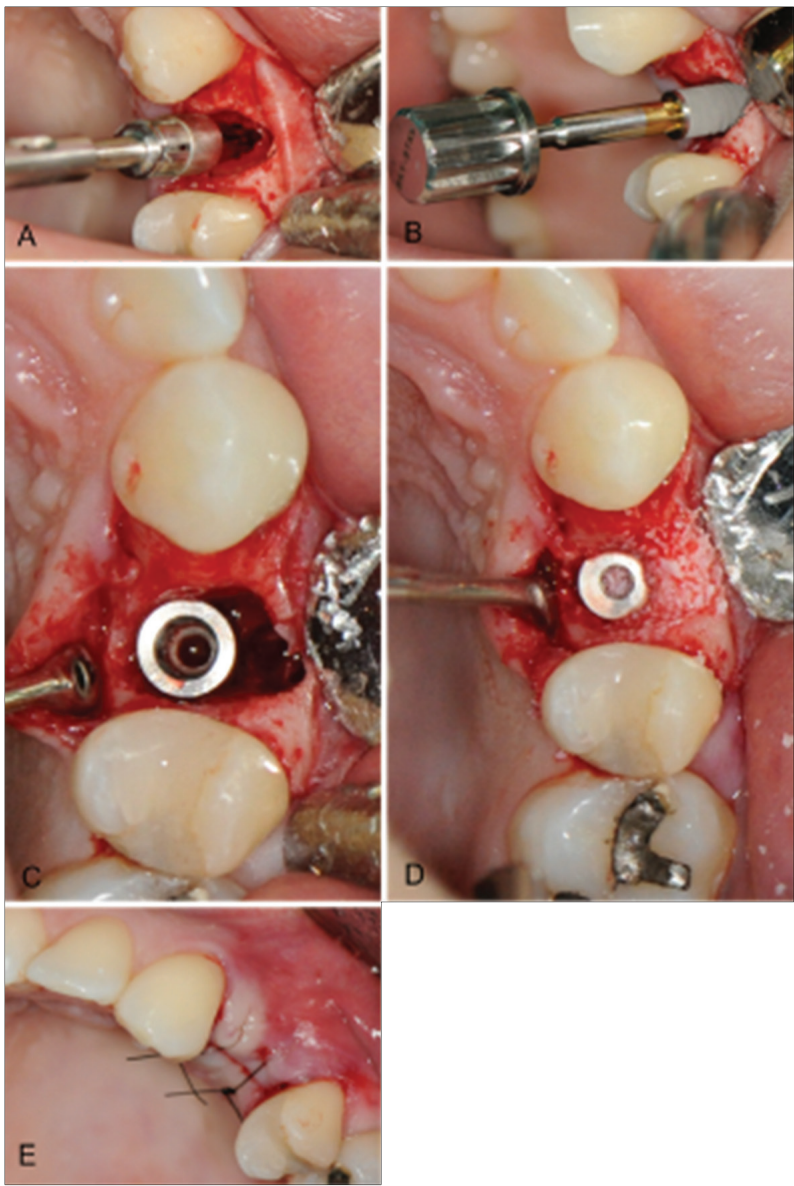

Figure 5. Site preparation (A); implant placement (B); adequate buccolingval position of implant (C); buccal gap filled with bone substitute (D); flap repositioned and sutured (E)

Slika 5. Preperacija ležišta implantata (A); ugradnja implantata (B); odgovarajuća bukolingvalna pozicija implantata (C); bukalni defekt popunjen koštanim zamenikom (D); repozicioniran i ušiven režanj $(E)$

level implant (Bredent ${ }^{\oplus} 4.0 \times 12 \mathrm{~mm}$ ) was inserted into the palatal socket (Figure 5A-E). With the intention of providing long term stability of bone and soft tissue support buccal alveolar socket was filled with bone substitute of low resorption rate and covered with absorbable membrane. Flap was repositioned and sutured with 5-0 nylon sutures. After six months implant was uncovered and definite prosthetic crown was delivered (Figure 6A-C).

\section{DISCUSSION}

Regardless of obvious clinical advantages decoronation is not widely accepted amongst practitioners even 3 decades after its introduction. Presumably, the main reason may be a limited number of evidence based research data addressing success rate of this procedure as well as constant pressure induced by medical companies in favor of use varied materials.

When it comes to bone preservation a variety of different grafting materials have been used for decades. More recently enamel matrix derivate (EMD) has been found to promote complete periodontal tissue regeneration and therefore it is recommended for the treatment of avulsed teeth [7]. However, more artificial materials is used, it is
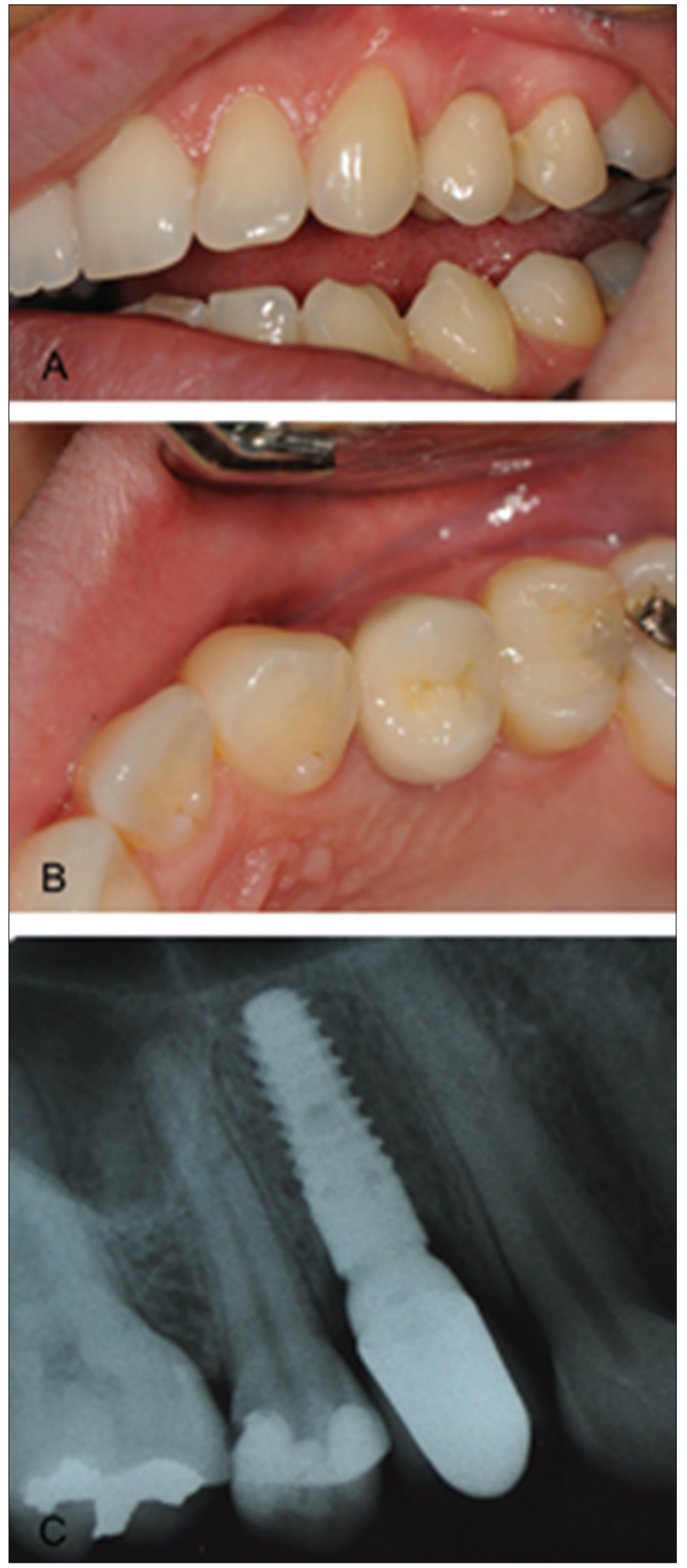

Figure 6. Definitive prosthetic solution: clinical (A, B) and radiological aspect (C)

Slika 6. Definitivno protetsko rešenje: klinički $(A, B)$ i radiološki aspekt (C)

higher the cost. On the other hand, it has been shown that not only bone preservation but also bone gain is to be expected after decoronation $[1,3,8,9,10]$. It is essential to highlight that effects on bone preservation and formation are time dependent. Namely, during pubertal growth spurt this procedure can greatly contribute to normal alveolar ridge development and after the growth peak is reached (by the age of 16) limited amounts of bone may be gained. Additionally, if decoronation was done before the occurrence of severe alveolar ridge deformation, tilting of the adjacent teeth could be reduced and accept- 
able soft tissue appearance could be established before implant placement. Our finding is consistent with those confirming bone and soft tissue gain. Moreover, when favorable gingival phenotype and bony socket walls are present acceptable healing by secondary intention will occur as a rule. By this approach mobilizing flap was avoided and mucogingival junction was left undisturbed which was crucial as its position may play an important role in long term implant stability regarding both function and aesthetics. Besides, it has been known for long time that every elevation of mucoperiosteal flap leads to the loss of crestal alveolar bone height irrespective of using partial or full thickness flap [11]. Hence, in those cases where anatomical conditions are encouraging more conservative approach is recommended.

On the contrary, Lin et al. showed that preservation of ridge width after decoronation was not $100 \%$ successful [4]. In this study a mean of $1.67 \mathrm{~mm}$ decrease in width was found with tendency to further decrease during time. Likewise, Tsukiboshi et al. concluded that decoronation procedure showed lack of bone preservation efficiency and related it to the loss of tooth dependent bone volume (TDBV) which is not genetically determined but based on vitality of periodontal fibers [12]. Nonetheless, based on existing literature data it can be emphasized that bone alterations after decoronation are similar to those found after using other preservation methods $[13,14,15]$.

While grafting procedure at the time of implant placement cannot be excluded by decoronation it can help to preserve sufficient bone volume for implant insertion and additional grafting is only used for long term implant stability [16]. Correspondingly, Filippi et al. reported slight decrease in width after two weeks following decoronation procedure that remained constant after 9 months follow up [17].

\section{CONCLUSION}

Along with literature evidences it can be concluded that decoronation might be a beneficial alternative regarding bone preservation prior to implant placement. This surgical procedure is a simple and conservative technique to avoid bone loss, aesthetic disturbances and excessively invasive treatments. In order to achieve best results careful diagnosis and right indication assessment are mandatory.

\section{REFERENCES}

1. Malmgren B, Cvek M, Lundberg M, Frykholm A. Surgical treatment of ankylosed and infrapositioned reimplanted incisors in adolescents. Eur J Oral Sci. 1984; 92(5):391-9. [DOI: 10.1111/j.1600-0722.1984. tb00907.x] [PMID: 6593804]

2. Malmgren B. Ridge preservation/decoronation. J Endod. 2013; 39(3 suppl):S67-72. [DOI: 10.1016/j.joen.2012.11.056] [PMID: 23439048]

3. Malmgren B, Malmgren O, Andreasen JO. Alveolar bone development after decoronation of ankylosed teeth. Endod Top. 2006; 14:3540. [DOI: 10.1111/j.1601-1546.2008.00225.x]

4. Lin S, Schwarz-Arad D, Ashkenazi M. Alveolar bone width preservation after decoronation of ankylosed anterior incisors. I Endod. 2013; 39(12):1542-4. [DOI: 10.1016/j.joen.2013.08.003] [PMID: 24238443]

5. Mohadeb JVN, Somar M, He H. Effectiveness of decoronation technique in the treatment of ankylosis: A systematic review. Dent Traumatol. 2016; 32(4):255-63. [DOI: 10.1111/edt.12247] [PMID: 26663218]

6. Horowitz R, Holtzclaw D, Rosen PS. A review on alveolar ridge preservation following tooth extraction. J Evid Based Dent Pract. 2012; 12(3 suppl.):149-60. [DOI: 10.1016/S1532-3382(12)70029-5] [PMID: 23040345]

7. Tuna EB, Yaman D, Yamamato S. What is the Best Root Surface Treatment for Avulsed Teeth? Open Dent J. 2014; 8:175-9. [DOI: 10.2174/1874210601408010175] [PMID: 25317212]

8. Malmgren B. Decoronation: How, Why and When? J Calif Dent Assoc. 2000; 28(11):846-54. [PMID: 11811233]

9. Cohenca N, Stabholz A. Decoronation - a conservative method to treat ankylosed teeth for preservation of alveolar ridge prior to permanent prosthetic reconstruction: literature review and case presentation. Dent Traumatol. 2007; (23):87-94. [DOI: 10.1111/j.16009657.2006.00454.x] [PMID: 17367456]

10. Sapir S, Kalter A, Sapir MR. Decoronation of an ankylosed permanent incisor: Alveolar ridge preservation and rehabilitation by an implant supported porcelain crown. Dent Traumatol. 2009; 25(3):346-9. [DOI: 10.1111/j.1600-9657.2009.00788.x] [PMID: 19583582]

11. Wood DL, Hoag PM, Donnenfeld OW, Rosenfeld LD. Alveolar Crest Reduction Following Full and Partial Thickness Flaps. J Periodontol. 1972; 43(3):141-4. [DOI: 10.1902/jop.1972.43.3.141] [PMID: 4501971]

12. Tsukiboshi M, Tsukiboshi T. Bone morphology after delayed tooth replantation - case series. Dent Traumatol. 2014; 30(6):477-83. [DOI: 10.1111/edt.12111] [PMID: 24720285]

13. Fickl S, Zuhr O, Wachtel H, Stappert CFJ, Stein JM, Hürzeler MB. Dimensional changes of the alveolar ridge contour after different socket preservation techniques. I Clin Periodontol. 2008; 35(10):90613. [DOI: 10.1111/j.1600-051X.2008.01305.x] [PMID: 18713258]

14. Fickl S, Schneider D, Zuhr O, Hinze M, Ender A, Jung RE, et al. Dimensional changes of the ridge contour after socket preservation and buccal overbuilding: An animal study. J Clin Periodontol. 2009; 36(5):442-8. [DOI: 10.1111/j.1600-051X.2009.01381.x] [PMID: 19419446]

15. Araújo MG, Silva CO, Misawa M, Sukekava F. Alveolar socket healing: What can we learn? Periodontol 2000. 2015; 68(1):122-34. [DOI: 10.1111/prd.12082] [PMID: 25867983]

16. Calasans-Maia JA, Neto AS, Batista MMD, Alves ATNN, Granjeiro JM, Calasans-Maia MD. Management of ankylosed young permanent incisors after trauma and prior to implant rehabilitation. Oral Surg. 2014; 7(1):45-51. [DOl: 10.1111/ors.12047]

17. Filippi A, Pohl Y, von Arx T. Decoronation of an ankylosed tooth for preservation of alveolar bone prior to implant placement. Dent Traumatol. 2001; 17(2):93-5. [DOI: 10.1034/j.16009657.2001.017002093.x] [PMID: 11475952] 


\title{
Dekoronizacija kao metod prezervacije alveolarnog grebena u cilju ugradnje implantata
}

\author{
Miroslav Dragović1, Marko Pejović ${ }^{1}$, Jelena Stepić1, Svetlana Dragović², Snježana Čolić1 \\ 'Univerzitet u Beogradu, Stomatološki fakultet, Klinika za oralnu hirurgiju, Beograd, Srbija; \\ ${ }^{2}$ Univerzitet u Beogradu, Stomatološki fakultet, Klinika za stomatološku protetiku, Beograd, Srbija
}

\begin{abstract}
KRATAK SADRŽAJ
Dekoronizacija je hirurška procedura koja ima za cilj uklanjanje krunice zuba i zadržavanja korena u alveoli radi sprečavanja nastanka značajnijih promena i poremećaja u koštanom i mekotkivnom kompleksu, koje mogu otežati kasniju protetsku rehabilitaciju pacijenta.

U ovom radu je prikazana dekoronizacija kod odrasle mlade pacijentkinje radi prezervacije (alveolarnog grebena) i stvaranja mekog tkiva za postavljanje implantata uz upotrebu minimalnih količina veštačkih materijala.

Ostvareni rezultati pokazali su da ova procedura može doprineti poboljšanju anatomskih uslova za ugradnju implantata uz značajnu redukciju invazivnosti, kao i finansijskih sredstava neophodnih za sprovođenje tehnike.

Ključne reči: dekoronizacija; ugradnja implantata; prezervacija alveole
\end{abstract}

\section{UVOD}

Dekoronizacija je prvi put opisana od strane Malmgrena i sar. pre više od 30 godina [1]. Ipak, sve do danas podaci iz literature koji obrađuju ovu temu su oskudni. Kao što se može zaključiti iz imena, ova procedura se bazira na ideji uklanjanja krunice zuba i zadržavanja korena u alveoli [2]. Originalno predložen kao terapijski protokol za tretiranje ankilotičnih sekutića u dečjem uzrastu posle traumatske avulzije, ovaj metod je doneo preokret u terapijskom pristupu problemu ankilotičnih zuba i omogućio stvaranje boljih uslova za postavljanje implantata posle završetka skeletnog razvoja. Iako primenom ovog metoda često dolazi do zamene zubnog tkiva koštanim, širina alveolarnog grebena ostaje očuvana $[3,4]$. Štaviše, zahvaljujući potencijalnom stvaranju novog koštanog tkiva, ugradnja implantata može biti minimalno invazivna [5]. Dva principa leže u osnovi stvaranja nove kosti. Inicijalno, posle uklanjanja krunice do nivoa 1-2 mm ispod krestalnog dela alveolarnog grebena dolazi do stvaranja krvnog ugruška koji predstavlja izvor faktora rasta koji utiču na osteoblaste da stvaraju novu kost. Osim toga, odsecanjem krunice ispod nivoa cervikalnog dela zuba interdentalna i cirkumferencijalna periodontalna vlakna ostaju bez uporišta omogućavajući nicanje susednih zuba. Napredovanje erupcije susednih zuba dovodi do stvaranja nove kosti na vrhu interdentalnog septuma putem apozicije [2].

$S$ druge strane, prezervacija alveole i alveolarnog grebena korišćenjem različitih materijala je dobro poznat način da se spreči gubitak kosti i obezbedi odgovarajući volumen koštanog tkiva za ugradnju implantata [6]. Međutim, ekonomski aspekt ili želja da se izbegne dodatna hirurška trauma prilikom uzimanja autolognog koštanog grafta su ponekad glavni razlozi zbog kojih se pacijenti odluče za neko jeftinije i manje invazivno rešenje za nadoknadu zuba.

Cilj ovog rada je prikaz upotrebe dekoronizacije kod mladog odraslog pacijenta u cilju prezervacije dovoljne količine kosti i stvaranja mekog tkiva za postavljanje implantata uz smanjenje potrebe za veštačkim materijalima.

\section{PRIKAZ PACIJENTA}

Dvadesetogodišnja pacijentkinja pregledana je klinički i radiološki na Klinici za oralnu hirurgiju Stomatološkog fakulteta Univerziteta u Beogradu. Budući da je prvi premolar u gornjoj vilici bio indikovan za vađenje, a da je očnjak intaktan, kao najbolje rešenje predložena je ugradnja implantata (Slika 1). Kako pacijentkinja nije bila u mogućnosti da se podvrgne ugradnji implantata u datom momentu, što zbog nedostatka finansijskih sredstava, što zbog psihološke nespremnosti za sprovođenje hirurške intervencije, u skladu sa podacima iz literature predložena je dokoronizacija kao privremno rešenje za očuvanje koštanog tkiva radi finansijskog olakšanja jer se time izbegava upotreba koštanih zamenika i membrane u ovoj fazi pripreme za ugradnju implantata. Uz saglasnost pacijentkinje, procedura je izvedena korišćenjem dijamantskog borera uz obilnu irigaciju u skladu sa preporukama iz literature [1]. Tehnika je izmenjena izostavljanjem horizontalne i vertikalne incizije (Slika 2).

Posle pet meseci pacijentkinja je odlučila da nastavi sa implantološkom terapijom. Uočeno je odlično mekotkivno zarastanje (Slika 3A). Urađena je krestalna incizija uključujući mezijalnu i distalnu papilu, posle čega je podignut mukoperiostalni režanj bez relaksacionih incizija. S obzirom na izvanredno koštano zarastanje, jedan deo stvorene kosti morao je biti uklonjen radi pristupanja potopljenim korenovima (Slika 3B). Korišćenjem periotoma, korenovi su izvađeni minimalno traumatski (Slika 4A-C). Prateći uobičajni hirurški protokol, postavljen je implantat standardnog dijametra (Bredent ${ }^{\circ}$ $4.0 \times 12 \mathrm{~mm}$ ) u palatinalnu alveolu (Slika 5A-E). S namerom da se obezbedi dugotrajna stabilnost koštanog i mekotkivnog profila oko implantata, bukalna alveola je popunjena spororesorptivnim veštačkim zamenikom za kost, preko čega je postavljena kolagena membrana. Mukoperiostalni režanj je repozicioniran i ušiven najlonskim koncem 5-0. Posle šest meseci izrađen je definitivni protetski rad (Slika 6A-C).

\section{DISKUSIJA}

Bez obzira na očigledne kliničke prednosti, dekoronizacija nije široko prihvaćen metod među kolegama ni posle tri decenije 
od prvog predstavljanja. Razlog za to može biti ograničen broj naučnih radova koji pokazuju stopu uspeha ove procedure, kao i konstantni pritisak od strane farmaceutskih kompanija u korist upotrebe različitih materijala za nadogradnju i očuvanje koštanog i mekog tkiva.

Dramatično veliki broj različitih materijala se koristi za prezervaciju kosti već godinama. Takođe, nešto skorije otkriveno je da gleđni proteini indukuju kompletnu regeneraciju parodontalnog kompleksa i preporučena je upotreba ovih preparata kod replantacije izbijenih zuba [7]. Međutim, tačno je i da veća količina upotrebljenih veštačkih materijala nosi sa sobom značajno veće finansijsko opterećenje za pacijente. $S$ druge strane, pokazano je da se dekoronizacijom može ostvariti ne samo očuvanje koštanog tkiva već i njegov dobitak $[1,3,8,9,10]$. Važno je istaći da efekat na očuvanje i stvaranje kosti zavisi od vremenskog okvira u kome se dekoronizacija izvodi. Naime, tokom pubertetskog naglog razvoja svih tkiva ova procedura može veoma mnogo doprineti normalnom razvoju alveolarnog grebena, dok po dostizanju vrhunca rasta i razvoja (oko 16. godine života) uticaj dekoronizacije na stvaranje nove kosti bitno opada. Isto tako, ukoliko se dekoronizacija uradi pre nastanka ozbiljnije deformacije alveolarnog grebena, inklinacija susednih zuba može se sprečiti i prihvatljiv izgled mekih tkiva može biti ostvaren, što je jedan od ključnih preduslova za uspeh kasnije implantološke terapije. Uz sva ograničenja, naš nalaz u prikazanom slučaju je u skladu sa istraživanjima koja potvrđuju uvećanje koštanog i mekotkivnog volumena. Štaviše, sa stanovišta autora ovog rada, zadovoljavajuće zarastanje čak i putem sekundarne intencije može se očekivati u slučajevima kad su očuvani koštani zidovi alveole i kad je prisutan povoljan gingivalni fenotip.

Ovakvim pristupom izbegava se odizanje mukoperiostalnog režnja i samim tim koronarno pomeranje mukogingivalne linije, što značajno doprinosi dugotrajnoj funkcionalnoj i estetskoj stabilnosti ugrađenog implantata. Osim toga, već dugo je poznato da svako odizanje mukoperiostalnog režnja, nezavisno od toga da li je u pitanju režanj pune debljine ili poludebljine, dovodi do gubitka kosti u krestalnom delu alveolarnog grebena [11]. Stoga, u onim slučajevima kad su ispunjeni anatomski preduslovi u smislu kvaliteta koštanog i mekog tkiva, preporučuje se konzervativniji pristup u svetlu moderne stomatološke filozofije „manje je više“.

Nasuprot istraživanjima koja govore u prilog dekoronizaciji, Lin i sar., su pokazali da prezervacija alveolarnog grebena posle dekoronizacije nije 100\% uspešna [4]. U ovoj studiji pronađeno je da srednja vrednost smanjenja širine alveolarnog grebena iznosi 1,67 mm sa tendencijom daljeg smanjenja kako vreme prolazi. Takođe, Tsukiboshi i sar., su zaključili da metod dekoronizacije nije efikasan u pogledu prezervacije alveolarnog grebana i to pripisali činjenici da postoji određena količina kosti koja nije genetski određena već da je zavisna od vitaliteta periodontalnih vlakana [12]. Bilo kako bilo, bazirano na postojećim dokazima iz literature, može se reći da su promene koštanog kompleksa posle dekoronizacije slične promenama koje se dešavaju posle primene nekih drugih metoda prezervacije $[13,14,15]$.

I dok se simultana nadogradnja koštanog tkiva u trenutku postavljanja implantata ne može sa sigurnošću isključiti dekoronizacijom, količina potrebnog materijala je značajno manja i služi samo kao osiguranje za dugotrajnu stabilnost implantata [16].S tim u vezi, Filippi i sar. su našli neznatno smanjenje širine alveolarnog grebena posle dve nedelje od dekoronizacije, ali je tokom sledećih devet meseci širina ostala nepromenjena [17].

U skladu sa nalazima iz literature, može se zaključiti da dekoronizacija predstavlja validnu alternativu za očuvanje kosti radi kasnije uspešne insercije implantata. Ova hirurška procedura predstavlja jednostavnu i konzervativnu tehniku kojom se mogu izbeći gubitak kosti, estetske nepravilnosti, kao i preterano invazivni terapijski protokoli. Radi ostvarenja najboljih rezultata upotrebom ove tehnike obavezni su pažljiva dijagnostika i pravilno postavljanje indikacije. 